\title{
A Encruzilhada do Plano Plurianual: entre a extinção e o fortalecimento ${ }^{1}$
}

Luiz Fernando Arantes Paulo²

\section{INTRODUÇÃO}

Após cerca de trinta anos da sua primeira experiência, o Plano Plurianual (PPA) se encontra em uma encruzilhada. De um lado, ameaçado de extinção, após ser desprestigiado por sucessivos governos. De outro, alvo de crescente interesse pelos órgãos de controle ${ }^{3}$ e por técnicos e acadêmicos, dada a centralidade conferida ao instrumento pela Constituição Federal de 1988 (CF/1988).

Por meio da Proposta de Emenda Constitucional (PEC) no 188, o governo federal formalizou a pretensão de extinguir o PPA, previsto no art. $165, \mathrm{I}, \$ 1^{\circ}{ }^{\circ},{ }^{4}$ e presente em diversos outros dispositivos constitucionais. Trata-se do principal instrumento de planejamento na administraçáo pública, ocupando função central no Sistema de Planejamento e Orçamento Federal. Em contrapartida, a mesma PEC propóe substituir a Lei Orçamentária Anual (LOA) pela Lei Orçamentária Plurianual, ${ }^{5}$ muito embora a fixação das despesas permaneça apenas para um único exercício. ${ }^{6}$

Caso aprovada a proposta, os governos recém-eleitos não serão mais obrigados a estabelecer diretrizes, objetivos e metas para as despesas orçamentárias, com vigência até o primeiro ano do mandato subsequente, como acontece desde 1990. Como estados e municípios também elaboram os seus PPAs, essa eventual alteraçáo da CF/1988 deve provocar grande impacto em todas as esferas de governo. ${ }^{7}$

A reação de técnicos, especialistas e juristas a uma possível extinção do PPA foi imediata. Apenas vinte dias após a publicação da PEC no Diário do Senado Federal, começaram a surgir artigos de opinião críticos à proposta em mídias de grande alcance, e mesmo dentro do principal think tank governamental da América Latina ${ }^{8}$ - o Ipea.

Como explicar esse descompasso entre a perspectiva política e a perspectiva técnica? Há alguma virtude na extinção do PPA? Há alternativas viáveis para o seu fortalecimento? São esses os questionamentos que este artigo pretende enfrentar. Para tanto, está estruturado em três seçôes, além desta introduçáo e da conclusão.

Primeiramente, buscou-se identificar as razóes para o atual ocaso do PPA que levaram o governo a incluir a proposta de sua extinção na $\mathrm{PEC} \mathrm{no} 188$. Em seguida, são apresentados os principais

1. DOI: http://dx.doi.org/10.38116/bapi27art1

2. Analista de planejamento e orçamento do governo federal desde 2004; mestre em direito e políticas públicas e especialista em gestão pública; e autor do livro Plano Plurianual: teoria, prática e desafios para sua efetividade. E-mail: <lfarantespaulo@gmail.com>.

3. Pela primeira vez, o Tribunal de Contas da União (TCU) acompanhou o processo de elaboração do PPA, conforme Acórdão nํ 2515/2019 - Plenário. 4. A lei que instituir o PPA estabelecerá, de forma regionalizada, as diretrizes, objetivos e metas da administração pública federal para as despesas de capital e outras delas decorrentes e para as relativas aos programas de duração continuada.

5. Haveria apenas uma estimativa para os demais exercícios, mas a proposta não estabelece qual seria essa plurianualidade, reservando essa definição à lei complementar a ser editada.

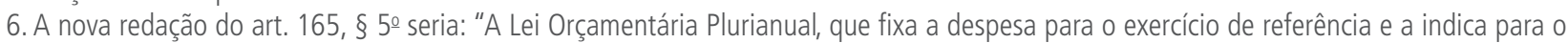
período definido em lei complementar, compreenderá (...)".

7. Sobre o papel do PPA na prática de planejamento nos municípios, ver Lima et al. (2020).

8. Segundo o relatório Global Go To Think Tank Index Report, produzido pela universidade americana da Pensilvânia e divulgado em 2019. 
argumentos presentes na reação à ideia de extinção do PPA, conforme artigos técnicos e de opinião considerados neste trabalho. Por fim, analisa-se a viabilidade de alternativas para o fortalecimento do PPA, considerados os fatores levantados nas seçôes anteriores.

É possível concluir que a proposta de extinção do PPA parece ser movida mais pelo interesse político em reduzir o controle sobre o planejamento e o orçamento governamentais que pelas reconhecidas fragilidades do instrumento e de sua gestáo, e que o seu fortalecimento, assim como de todo o sistema de planejamento e orçamento insculpido na CF/1988, depende do constrangimento dos detentores do poder político pelos atores com legitimidade democrática.

\section{RAZÕES PARA O OCASO DO PPA}

O PPA e os seus mecanismos de gestão estão, há tempos, sob um processo contínuo e progressivo de esvaziamento, especialmente a partir do lançamento do Programa de Aceleração do Crescimento (PAC), no início de 2007 (Paulo, 2016, p. 19). O desprestígio do plano com a alta administração pública federal é tamanho que a proposta de sua extinção, presente na $\mathrm{PEC} \mathrm{n}^{\circ}$ 188, sequer foi acompanhada de alguma justificativa.

Nesta seção, apontamos fatores que, a nosso ver, podem explicar o ocaso pelo qual o PPA atravessa e o desejo do governo federal de promover a sua extinção.

Primeiramente, é necessário reconhecer que a ideia de formalizar um planejamento, por si só, representa um constrangimento aos governantes, ao passo que estabelece critérios objetivos para avaliação do seu desempenho. Não é de se estranhar, portanto, a intenção política de retirar da Constituição compromissos dessa natureza.

Considerando-se a dinâmica político-eleitoral existente no Brasil, multipartidária e com pleitos a cada dois anos, os governantes são submetidos a intermináveis repactuaçóes com grupos de apoio, especialmente ligadas à rápida satisfação de demandas orçamentárias. ${ }^{9}$ Nesse contexto, a vinculação a um planejamento prévio pode dificultar a formação de apoio político. ${ }^{10}$

A resistência ao PPA não reside apenas na dinâmica político-eleitoral, mas também em questionamentos acerca da indefinição do seu papel no sistema de planejamento e orçamento construído na $\mathrm{CF} / 1988 .{ }^{11}$ De fato, a proposta de sua extinção parece significar que outros instrumentos poderiam cumprir suas funçóes, tal como a absorção das orientaçóes estratégicas por um Plano Nacional de Desenvolvimento $^{12}$ e a discriminaçáo de investimentos prioritários pelo orçamento plurianual, por exemplo. Não compete a este trabalho debater sobre a função primordial a ser atribuída ao PPA, mas apenas destacar que essa imprecisão, certamente, contribui para a proposta de extinção presente na PEC n⿳⺈ $188 .{ }^{13}$

Há confusão se os compromissos descritos no plano devem ser restritos à esfera federal, ou se devem considerar a participação e a cooperação dos demais entes subnacionais. Esse debate é

9. Sobre os custos para governar por meio do presidencialismo de coalisão no Brasil, ver Bertholini e Pereira (2017).

10. Acerca da precariedade no nosso sistema para definição de prioridades e coordenação das políticas e o seu impacto no sistema orçamentário, ver Fortis e Gasparini (2017, especialmente p. 194-197).

11. Nesse sentido, ver Couto e Cardoso Júnior (2020, p. 26).

12. A CF/1988 dispõe sobre planos nacionais de desenvolvimento, que devem integrar os planos regionais de desenvolvimento e ser incorporados e compatibilizados pelas diretrizes e bases do desenvolvimento nacional equilibrado. Atualmente, aproxima-se desse ideal a Estratégia Nacional de Desenvolvimento Econômico e Social (Endes), contudo, sem força de lei.

13. Para distintas visões acerca do papel do PPA, ver Garcia (2012), Paulo (2016) e Couto e Cardoso Júnior (2020). 
especialmente relevante em políticas de segurança pública e sociais, como saúde e educação, nas quais o governo federal tem importante participação no financiamento e coordenação, mas há considerável autonomia dos demais entes para a organização dos serviços públicos. O PPA federal deveria considerar os resultados finais da política pública percebidos pela sociedade ou apenas aqueles sob sua integral governabilidade?

No mesmo sentido, nunca esteve claro se os compromissos a serem formalizados no PPA devem ser apenas os financiados por despesas orçamentárias, ou se devem ser consideradas as demais estratégias presentes nas finanças públicas, tais como renúncias tributárias, financiamentos de agências oficiais, entre outras (Couto e Cardoso Júnior, 2020, p. 17).

Diante do desapreço político pelo instrumento e considerando-se as importantes indefiniçóes normativas apontadas em breve síntese até aqui, é possível compreender as constantes rupturas no modelo e na estrutura do PPA, além do pouco interesse em aprovar a lei complementar que deve lhe dar contornos mais precisos.

Independentemente da estrutura e conteúdo imprecisos, é na gestão do PPA o mais flagrante desprestígio. $\mathrm{Na}$ atual estrutura, a unidade responsável pela coordenação do PPA foi deslocada para o quarto escalão do Ministério da Economia, ${ }^{14}$ com reduzida influência na tomada de decisão no centro de governo, bem como nos órgãos setoriais.

É preciso ter clareza de que o empoderamento de uma gestão técnica do PPA reduz consideravelmente a margem de manobra dos agentes políticos. Em outras palavras, profissionalizar a gestão do PPA tende a limitar o poder do governante de plantão, assim como das demais forças políticas que negociam seu apoio ao governo.

Exemplo claro dessa tensão entre perspectivas técnica e política ocorreu no lançamento do PAC no início de 2007. Àquela altura, havia se institucionalizado uma avaliação de pré-viabilidade para todos os projetos de investimento de grande vulto (à época, acima de R \$ 10,5 milhóes), sendo que a inclusão de ação no Projeto de Lei Orçamentária estava condicionada à aprovação do projeto pela Comissão de Monitoramento e Avaliação (CMA), ${ }^{15}$ composta por representantes do então Ministério do Planejamento, da Fazenda e da Casa Civil da Presidência da República.

Não obstante o mérito evidente de uma avaliação de projetos anteriormente ao comprometimento da dotação orçamentária, o procedimento adotado acabava por comprometer a formação de acordos políticos e o anúncio de novos empreendimentos. A fim de "acelerar" os investimentos (e satisfazer acordos políticos), todos os projetos incluídos no PAC foram dispensados de análise pela CMA.

Daí em diante, a gestão do PPA foi se tornando cada vez mais frágil, tendo como principal norte o não constrangimento às decisóes políticas, culminando com um novo modelo de plano (PPA 2012-2015) com fraco respaldo técnico e metodológico e um modelo de gestão distanciado das definiçốes de alocação orçamentária (Paulo, 2016).

Finalmente, a regionalização, disposta expressamente na CF/1988 como essencial ao PPA, nunca se deu de forma efetiva. Seu enfoque sempre foi setorializado, inexistindo um canal de comunicação

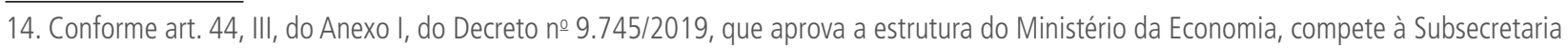
de Planejamento Governamental "estabelecer diretrizes e normas, coordenar, orientar e supervisionar a elaboração, a implementação, 0 monitoramento e a avaliação do plano plurianual".

15. Portaria Interministerial MP/MF/CCPR ํo 10, de 11 de janeiro de 2005, art. 3ํ. 
estruturado e institucionalizado com as unidades de planejamento subnacionais, especialmente estados e Distrito Federal.

Diante desse quadro de desinteresse político, fragilidade técnica e baixa institucionalidade, é possível compreender a proposta de extinção do PPA apresentada na PEC n⿳0 188.

\section{REAÇÕES À PROPOSTA DE EXTINÇÃO DO PPA}

Apesar do quadro desfavorável ao PPA visto anteriormente, a proposta de sua extinção, pura e simples, provocou imediata reação de juristas, técnicos e especialistas em gestão pública.

Para Conti (2020), o PPA é o principal instrumento de planejamento da administração pública, e o seu desprestígio é seguramente um dos principais motivos da ineficiência da máquina pública. $\mathrm{O}$ autor entende que o PPA nunca conseguiu dar segurança jurídica, mas "parece mais adequado corrigir as distorçóes e criar a cultura do planejamento do que abandoná-lo ou mitigá-lo”. Nesse sentido, o plano deveria favorecer a ação coordenada e a cooperação entre os entes federativos.

Para Pinto (2019), o PPA equaliza duas funçôes estruturais do Estado brasileiro: fomento ao mercado e prestação de serviços públicos. A procuradora do Ministério Público de Contas de São Paulo aponta que a primazia do fomento ao mercado ameaça a continuidade de serviços públicos, a exemplo da vinculação de receitas a compromissos fiscais, enquanto veda a mesma estratégia para o planejamento de gastos em programas governamentais.

A autora defende o papel do PPA na ordenação legítima das prioridades orçamentárias e financeiras e destaca que "fora do PPA, não há equacionamento legítimo da disputa orçamentária entre fomento ao mercado e serviços públicos essenciais, porque a tendência é de deixarmos os programas de duração continuada expostos à desconstrução da sua prioridade intertemporal” (Pinto, 2019).

Para Couto e Cardoso Júnior (2020, p. 51), “o PPA tem a particularidade de reunir o conjunto de políticas públicas dos mais variados setores, com a possibilidade de promover integração entre estes, reforçando agendas intersetoriais e mediando possíveis conflitos entre setores com distintas perspectivas".

Para os autores, a eventual extinção do PPA pode aumentar a instabilidade no regime de governança orçamentária e ampliar os riscos de desestruturação das políticas públicas.

Para Scaff (2020), o PPA é visto como um plano estratégico e não pode ser dispensado em função da introdução de um orçamento plurianual. Uma, porque esse orçamento plurianual já se encontra previsto na Constituição no art. $165, \$ 14,{ }^{16}$ outra, porque se trata de exercícios diferentes. Uma orçamentação só poderia existir a partir de um exercício de planejamento.

Para Zuccolotto, Azevedo e Pigatto (2020), o PPA “pode ser definido como um planejamento orçamentário de médio prazo, que permite o monitoramento dos resultados dos diversos programas governamentais existentes e, em tese, permitiria a responsabilização dos governantes eleitos e da burocracia pública", sendo "um importante instrumento de accountability democrática". Para os autores, o PPA abriria caminho para o ganho de eficácia e eficiência na administração pública por meio do "gerencialismo".

16. Incluído pela Emenda Constitucional no 102/2019, in verbis: “A lei orçamentária anual poderá conter previsões de despesas para exercícios seguintes, com a especificação dos investimentos plurianuais e daqueles em andamento". 
Para Paulo (2019), a importância do PPA ultrapassa o seu sentido econômico, uma vez que consiste em um importante instrumento de defesa da democracia. Ao condicionar as decisóes referentes a despesas públicas a um planejamento prévio, o PPA estabelece limites aos detentores do poder político, sendo que a proposta de extinção do PPA "parece selar a vitória dos interesses políticos de curto prazo sobre a profissionalização da administração e qualificação dos gastos públicos” (op. cit.).

\section{ALTERNATIVAS (E VIABILIDADE) PARA FORTALECIMENTO DO PPA}

A fragilidade do planejamento governamental no Brasil, e do PPA em especial, não pode ser atribuída à falta de legislação. $\mathrm{A} \mathrm{CF} / 1988$ privilegiou a função planejamento ${ }^{17}$ e construiu um sistema robusto integrado ao orçamento, como um caminho institucional para a realização de direitos (Paulo, 2016). Assim, ao passo que protege o regime democrático, também direciona a administração aos objetivos fundamentais da República (op. cit.).

Embora a lei complementar prevista no art. 165, $\$ 99^{\circ 18}$ ainda não tenha sido aprovada, o Sistema de Planejamento e Orçamento Federal conta com um importante marco legal, a Lei no 10.180/2001, que o disciplina e organiza.

Entre outras coisas, essa lei estabelece que compete às unidades responsáveis pelas atividades de planejamento acompanhar e avaliar a execução de planos e programas, ${ }^{19}$ quanto à eficácia e efetividade, com vistas a "subsidiar o processo de alocação de recursos públicos, a política de gastos e a coordenação das açôes de governo". Também compete a essas unidades "identificar, analisar e avaliar os investimentos estratégicos do governo, suas fontes de financiamento e sua articulação com os investimentos privados, bem como prestar o apoio gerencial e institucional à sua implementação" (art. 7o, VI, grifo nosso).

Não obstante o respaldo constitucional e legal, as atividades mencionadas não se encontram estruturadas até hoje (Couto, 2011). De fato, as iniciativas neste sentido foram rapidamente descontinuadas, a exemplo do ocorrido no embate entre CMA e PAC e o abandono das Unidades de Monitoramento e Avaliação nos órgãos setoriais (Serpa, 2011).

Trata-se, portanto, de um debate que ultrapassa a extinção ou não do PPA, de como tornar o sistema de planejamento e orçamento, protegido por robusto arcabouço normativo, efetivo. Em razáo da mencionada oposição dos detentores do poder político, é evidente a necessidade de participação de outros atores nessa dinâmica, especialmente aqueles dotados de legitimidade democrática (Barroso, 2009), como os Tribunais de Contas (Heller, 2020; Britto, 2001), o Ministério Público (Casagrande, 2002) e o Poder Judiciário (Guerra, 2008; Barcellos, 2005).

É nesse contexto que merece destaque o inédito acompanhamento do processo de elaboração do PPA 2020-2023 pelo TCU, resultando no Acórdão no 2515/2019 TCU Plenário. ${ }^{20}$ A atuação do TCU apresenta recomendaçóes ao Ministério da Economia e à Casa Civil da Presidência da

17. Veloso (2014) destaca que 16\% dos dispositivos constitucionais fazem referência a planejamento.

18. "Cabe à lei complementar: I - dispor sobre o exercício financeiro, a vigência, os prazos, a elaboração e a organização do plano plurianual, da lei de diretrizes orçamentárias e da lei orçamentária anual; (...)".

19. Planos e programas nacionais e setoriais de desenvolvimento econômico e social e o PPA (art. 7ํㅡ, III).

20. A auditoria se propôs a investigar se "a proposta do PPA 2020-2023 elaborada pelo Executivo possui os requisitos necessários para que seja considerada um instrumento efetivo de planejamento de médio prazo do governo federal, que expresse de forma adequada as intenções governamentais, oriente a execução do gasto público e viabilize o monitoramento e a avaliação da atuação governamental durante a sua vigência" (Brasil, 2019). 
República e informaçóes ao Congresso Nacional, no intuito de o PPA 2020-2023 atender aos preceitos constitucionais e servir de instrumento efetivo de orientação da gestão e de monitoramento e avaliação.

Apesar dessa importante atuação do TCU, a apresentação de recomendaçóes (e não determinaçóes) não dispóe de força coercitiva suficiente para romper a resistência política à implementação das medidas necessárias.

A nosso ver, considerando o papel central do sistema de planejamento e orçamento, e do PPA, na proteção ao regime democrático, ${ }^{21}$ compete também ao Ministério Público, com fundamento no art. $127 \mathrm{da} \mathrm{CF} / 1988,{ }^{22}$ propor as açóes cabíveis para a sua efetiva implementação, especialmente para provocar soluçóes negociadas entre os Poderes da República, possivelmente por meio de diálogos institucionais (Clève e Lorenzetto, 2015).

Não se trata de interferir no mérito das escolhas políticas, ${ }^{23}$ mas garantir que a administração pública obedeça aos princípios inscritos no art. 37 da CF/1988, especialmente o da eficiência.

Nesse sentido, é preciso garantir, por exemplo, que as atividades de planejamento exerçam influência sobre a alocação de recursos públicos, bem como que as unidades de planejamento avaliem os investimentos estratégicos do governo, tal como disposto na Lei no 10.180/2001. Em caso de omissão da administração, faz-se necessária a atuação do controle externo e/ou jurisdicional.

Com isso, é possível que o resultado seja o fortalecimento do sistema de planejamento e orçamento como um todo, e do PPA em especial, superando a natural resistência dos detentores do poder político e promovendo um aperfeiçoamento progressivo e constante do setor público.

\section{CONCLUSÃO}

A proposta de extinção do PPA contida na PEC no 188 parece ser movida mais pelo interesse político em reduzir o controle sobre planejamento e orçamento governamentais que pelas reconhecidas fragilidades do instrumento e de sua gestão.

O fortalecimento do PPA, no entanto, está inserido em um contexto maior, de pleno cumprimento das atividades de planejamento estabelecidas no âmbito do Sistema Federal de Planejamento e Orçamento, e depende da mobilização dos atores com legitimidade democrática, em razão do choque evidente com interesses imediatos dos governantes e a dinâmica de formação de apoio político no Brasil.

21. Para saber mais como o sistema de planejamento e orçamento deve exercer controle sobre o governo e, com isso, proteger o regime democrático, ver Paulo (2016).

22. O Ministério Público é instituição permanente, essencial à função jurisdicional do Estado, incumbindo-Ihe a defesa da ordem jurídica, do regime democrático e dos interesses sociais e individuais indisponíveis.

23. Uma abordagem didática sobre as relações Direito, política e democracia, especialmente sobre a distinção entre procedimentalismo e substancialismo, está em Lima (2017). 0 argumento trazido neste texto filia-se à corrente procedimentalista. 


\section{REFERÊNCIAS}

BARCELLOS, Ana Paula de. Neoconstitucionalismo, direitos fundamentais e controle das políticas públicas. Revista Direito Administrativo, Rio de Janeiro, n. 240, p. 83-103, 2005.

BARROSO, Luís Roberto. Judicialização, ativismo judicial e legitimidade democrática. Anuário Iberoamericano de Justicia Constitucional, Madrid, n. 13, p. 17-32, 2009.

BERTHOLINI, Frederico; PEREIRA, Carlos. Pagando o preço de governar: custos de gerência de coalizão no presidencialismo brasileiro. Revista de Administração Pública, Rio de Janeiro, v. 51, n. 4, p. 528-550, ago. 2017.

BRASIL. Tribunal de Contas da União. Plenário. Relatório e Acórdão n. 2515, 2019.

BRITTO, Carlos Ayres. O regime constitucional dos tribunais de contas. Revista Diálogo Jurídico, Salvador: Centro de Atualização Jurídica (CAJ), v. I, n. 9, 2001.

CASAGRANDE, Cássio. Ministério Público, Ação Civil Pública e a judicialização da política perspectivas para o seu estudo. Boletim Científico Escola Superior do Ministério Público da União, Brasília, a. I, n. 3, p. 21-34, 2002.

CLÈVE, Clèmerson Merlin; LORENZETTO, Bruno Meneses. Diálogos institucionais: estrutura e legitimidade. Revista de Investigaçóes Constitucionais, Curitiba, v. 2, n. 3, p. 183-206, 2015.

CONTI, José Maurício. Os planos do governo Bolsonaro e a necessidade de fortalecimento do planejamento. Coluna Fiscal, Portal JOTA, 16 jan. 2020. Disponível em: <https://www.jota. info/opiniao-e-analise/colunas/coluna-fiscal/os-planos-do-governo-bolsonaro-a-necessidade-defortalecimento-do-planejamento-16012020>.

COUTO, Leandro Freitas. Sistema de planejamento federal: novas respostas para velhos e novos desafios. Revista Brasileira de Planejamento e Orçamento, Brasília, v. 1, n. 1, p. 4-14, 2011.

COUTO, Leandro Freitas; CARDOSO JÚNIOR, José Celso. A função dos planos plurianuais no direcionamento dos orçamentos anuais: avaliação da trajetória dos PPAs no cumprimento da sua missão constitucional e o lugar do PPA 2020-2023. Brasília: Ipea, mar. 2020. (Texto para Discussão, n. 2549).

FORTIS, Martin Francisco de Almeida; GASPARINI, Carlos Eduardo. Plurianualidade orçamentária no Brasil: diagnóstico, rumos e desafios. Brasília: Enap, 2017.

GARCIA, Ronaldo Coutinho. PPA: o que não é e o que pode ser. Políticas sociais: acompanhamento e análise. Brasília: Ipea, n. 20, p. 431-456, 2012.

GUERRA, Gustavo Rabay. O papel político do Judiciário em uma democracia qualificada: a outra face da judicialização da política e das relaçóes sociais. Revista Direitos Fundamentais \& Democracia, v. 4, 2008.

HELLER, Gabriel. Diálogos institucionais e participação social: a legitimidade do Tribunal de Contas no controle de políticas públicas. Revista Direito das Políticas Públicas, v.1, n. 2, p. 148-171, 2020.

LIMA, Luciana Leite et al. Planejamento governamental nos municípios brasileiros: em direção a uma agenda de pesquisa. Cadernos EBAPE.BR, Rio de Janeiro, v.18, n. 2, abr./jun. 2020. 
LIMA, Thadeu Augimeri de Goes. Processo jurisdicional e política na democracia constitucional: parte 1. Revista Jus Navigandi, Teresina, ano 22, n. 4971, 2017.

MCGANN, James. Global Go To Think Tank Index Report. University of Pennsylvania, Think Tanks and Civil Societies Program, 2019.

PAUlO, Luiz Fernando Arantes. Plano Plurianual: teoria, prática e desafios para sua efetividade. Curitiba: Juruá, 2016.

Extinçáo do Plano Plurianual é retrocesso: a intrigante incoerência escondida no Plano Mais Brasil. Coluna Opinião, Portal do Jornal Folha de S. Paulo, 26 nov. 2019. Disponível em: <https://www1.folha.uol.com.br/opiniao/2019/11/extincao-do-plano-plurianual-e-retrocesso. shtml?origin=folha>.

PINTO, Élida Graziane. Como equalizar investimentos e programas de duração continuada sem PPA?. Coluna Contas à Vista, Portal Consultor Jurídico, 3 dez. 2019. Disponível em: <https://www. conjur.com.br/2019-dez-03/contas-vista-equalizar-investimentos-programas-duracao-continuada-ppa> .

SCAFF, Fernando Facury. A PEC 188 e a destruiçáo do planejamento governamental. Coluna Contas à Vista, Portal Consultor Jurídico, 3 mar. 2020. Disponível em: <https:/www.conjur.com. br/2020-mar-03/contas-vista-pec-188-destruicao-planejamento-governamental>.

SERPA, Selma Maria Hayakawa Cunha. Levantamento do Tribunal de Contas da União sobre os sistemas de monitoramento e avaliação da administração direta do Poder Executivo. Revista Brasileira de Monitoramento e Avaliação, n. 2, 2011.

VELOSO, Juliano Ribeiro Santos. Direito ao planejamento. Belo Horizonte: D’Plácido, 2014. ZUCCOLOTTO, Robson; AZEVEDO, Ricardo Rocha de; PIGATTO, José Alexandre. Quando o remédio mata o paciente: o planejamento orçamentário brasileiro e a proposta de extinção do Plano Plurianual. Blog Gestão, Política \& Sociedade, Portal do Jornal O Estado de S. Paulo, 11 jun. 2020. Disponível em: <https://politica.estadao.com.br/blogs/gestao-politica-e-sociedade/ quando-o-remedio-mata-o-paciente-o-planejamento-orcamentario-brasileiro-e-a-proposta-deextincao-do-plano-plurianual/?utm_source=estadao\%3Afacebook\&fbclid=IwAR1TNUm_ O0j1xhXJCq82OpQy7xfGnM5ASeLmODOGYn1EOfI65_ihBopD7HE>. 